\title{
COMPETÊNCIAS DOS PROFESSORES PARA O SÉCULO XXI: UMA ABORDAGEM METODOLÓGICA MISTA DE INVESTIGAÇÃo
}

\author{
Ana PEDRO ${ }^{1}$ \\ João Filipe MATOS ${ }^{2}$
}

\begin{abstract}
RESUMO
Tendo-se teoricamente debruçado sobre o conceito de competência, esta investigação procurou identificar quais as competências técnico-pedagógicas do século XXI necessárias a um professor do ensino básico. No campo empírico, adotou-se uma abordagem metodológica mista, estruturada a partir de um paradigma pragmático, tendo sido recolhidos dados quantitativos, através da aplicação da escala de perceção de competências docentes para o século XXI a 2688 professores do $2^{\circ}$ e $3^{\circ}$ ciclo do Ensino Básico português, e dados qualitativos, realizando entrevistas a cinco stakeholders do sistema educativo português. Os resultados obtidos, em ambas as recolhas, foram posteriormente cruzados, dando origem a uma proposta de referencial de competências para o século XXI para professores do $2^{\circ}$ e $3^{\circ}$ ciclo do Ensino Básico português, composto por 37 competências, organizadas em quatro dimensões (pedagógica, profissional, tecnológica e de relações interpessoais e institucionais). A partir destes dados procurou-se refletir sobre as implicações do referencial de competências para o séc. XXI no desenvolvimento profissional docente.
\end{abstract}

PALAVRAS-CHAVE: Competências docentes; Competências para o séc. XXI; Desenvolvimento profissional docente; Metodologias mistas de investigação.

\section{TEACHERS' SKILLS FOR XXI CENTURY: A MIXED METHODS APPROACH}

\begin{abstract}
Having studied the theoretical concept of competence, this research aimed to identify the technical and pedagogical skills needed by teachers in the 21st century. On empirical field, we adopted a mixed methods approach based on a pragmatic paradigm. Data was gathered (i) applying a scale of perception of teaching competencies for the 21 st century to 2688 portuguese teachers and (ii) interviewing five stakeholders of the portuguese educational system. Results allowed to produce 37 competencies organized around four dimensions: pedagogical; professional; technological; interpersonal and institutional relations. From these data, we reflected on the XXI century skills for teachers framework implications in teachers professional development.
\end{abstract}

\footnotetext{
${ }^{1}$ Doutorada em Educação - TIC na Educação, pela Universidade de Lisboa e Mestre em Psicologia Aplicada área Educacional. Atualmente é professora Auxiliar Convidada no Instituto de Educação da Universidade de Lisboa, assumindo também a co-coordenação do Centro de Competência em Tecnologias e Inovação do Instituto de Educação. Membro do grupo de investigação Educação, Tecnologia e Sociedade (ETS) do Instituto de Educação da Universidade de Lisboa. E-mail: aipedro@ie.ulisboa.pt

${ }^{2}$ Doutorado em Educação - Didática das Ciências, pela Universidade de Lisboa, com Agregação em Educação. Atualmente é Professor Catedrático do Instituto de Educação da Universidade de Lisboa e investigador da Unidade de Investigação e Desenvolvimento em Educação e Formação. Coordena o E-learning Lab da Universidade de Lisboa. No Instituto de Educação é diretor do programa de doutoramento em educação no tema Technology Enhanced Learning and Societal Challenges financiado pela FCT e coordenador do Mestrado em Educação e Formação na especialidade de E-learning e Formação a Distância e do Curso Pós-graduado de Especialização em Tecnologias e Metodologias da Programação no Ensino Básico. E-mail: jfmatos@ie.ulisboa.pt
}

Revista e-Curriculum, São Paulo, v.17, n.2, p.344-364 abr./jun. 2019

Programa de Pós-graduação Educação: Currículo - PUC/SP

http://revistas.pucsp.br/index.php/curriculum 


\title{
e-Curriculum
}

KEYWORDS: Teachers' Competencies; 21st Century Skills; Teachers' Professional Development; Mixed Methods Approach.

\section{COMPETENCIAS DE LOS PROFESORES PARA EL SIGLO XXI: UN ENFOQUE METODOLÓGICO MISTA DE INVESTIGACIÓN}

\begin{abstract}
RESUMEN
Habiendo abordado el concepto teórico de competencia, esta investigación buscó identificar cuáles las competencias técnico-pedagógicas del siglo XXI necesarias a un profesor de enseñanza básica. En el campo empírico, se adoptó un enfoque metodológico misto, estructurado a partir de un paradigma pragmático, habiendo sido recogidos datos cuantitativos, a través de la aplicación de la escala de percepción de competencias docentes para el siglo XXI a 2688 profesores del $2^{\circ}$ y $3^{\circ}$ ciclo de la Enseñanza datos portuguesas y cualitativos básicos, la realización de entrevistas a cinco actores del sistema educativo portugués. Los resultados en ambas colecciones fueron más tarde cruzados, lo que lleva a una propuesta de referencia habilidades para el siglo XXI a 2 de los profesores y 3er ciclo de educación básica portugués, compuesto de 37 competencias, dispuestos en cuatro dimensiones (educativo, profesional, tecnológica y de relaciones interpersonales e institucionales). A partir de estos datos se buscó reflexionar sobre las implicaciones del referencial de competencias para el s. XXI en el desarrollo profesional docente.
\end{abstract}

PALABRAS CLAVE: Competencias docentes; Competencias para el sec. XXI; Desarrollo profesional docente; Metodologías mistas de investigación.

\section{INTRODUÇÃO}

Nos últimos anos, as competências para o séc. XXI dos professores e as atitudes destes face à utilização de tecnologias têm estado no centro da modernização das práticas pedagógicas (Comissão Europeia, 2013; OECD, 2013; 2016). Efetivamente, a utilização de tecnologias em atividades didáticas e pedagógicas, e o consequente desenvolvimento de competências neste domínio, não têm sido uma realidade efetiva nas práticas docentes em diversos países (BATANE \& NGWAKO, 2017; 2015; LILLEJORD, BØRTE, NESJE \& RUUD, 2018).

De facto, a conceptualização da atividade docente tem sido encarada como um objeto de análise e de discussão, acompanhando as diferentes alterações vividas dentro do sistema educativo (NÓVOA, 2003). Na mesma linha, Jesus (2000) assinalara a necessidade de se pensar a docência a um nível macro e a um nível micro, analisando aspetos quer relacionados com o contexto sociopolítico, social e cultural (a um nível macro), quer com as condições de trabalho, com o clima de sala de aula ou com as alterações curriculares (a um nível micro). 
Em paralelo às modificações vivenciadas nos diferentes contextos (políticos, sociais, culturais, curriculares, etc.) assinalam-se também os avanços registados no desenvolvimento das tecnologias digitais e nas possibilidades de comunicação que o acesso democrático à informação trouxe, tais como a proliferação e popularização das tecnologias móveis através de novas gerações de smartphones, tablets ou microcomputadores cada vez mais potentes.

A escola é, em todos os níveis de ensino, habitada por alunos que nasceram e cresceram num mundo saturado de media, que sempre estiveram imersos em tecnologias digitais e para quem é difícil conceber o seu dia-a-dia sem smartphones, tablets ou outra tecnologia (PEDRO, WUNCH, PEDRO \& MATOS, 2010). São estes os jovens do século XXI para quem a noção de escola e de prática escolar está em questão. Reconhecendo a diferenciação (provavelmente necessária) entre as práticas escolares e as não escolares, quer da parte dos alunos, quer da parte dos pais e professores, torna-se fundamental perceber qual é a vocação da escola e qual é o seu contributo para a criação e consolidação das competências adequadas à ação em contextos diversificados e ao seu desenvolvimento ao longo da vida.

Importa do mesmo modo trazer ao enquadramento desta problemática a noção de que, atualmente, professores e alunos falam diferentes linguagens expressas em reportórios distintos, por viverem imersos em contextos muito diferenciados onde as práticas em que participam não podem ser desligadas dos seus contextos histórico-sociais e das suas comunidades de pertença (MATOS \& PEDRO, 2011). Esta ideia está em concordância com os resultados empíricos encontrados por Pedro et al. (2010), que indicaram que os alunos viam como necessário considerar na formação docente na área das tecnologias digitais, nomeadamente no que respeita à eleição e utilização de novas ferramentas digitais, novas competências e novos conteúdos.

Pretende-se assim entender de que modo as alterações e mudanças referidas têm impacto na necessidade de repensar as competências dos professores no quadro escolar, trazendo contributos para a reflexão necessária ao desenvolvimento prospetivo da docência à luz do desenvolvimento tecnológico atual. A análise desta problemática torna pertinente refletir sobre quais as competências para o século XXI que são cruciais que os professores desenvolvam, de forma a que estes possam promover e garantir que os seus alunos se encontrem aptos a obter sucesso pessoal, profissional, cultural e relacional. 


\section{e-Curriculum}

\section{ENQUADRAMENTO TEÓRICO}

O conceito de competência tem sido objeto de conceções diversas, diferindo a sua definição consoante os autores que o utilizam nos seus trabalhos. A este conceito, considerado complexo, têm sido associadas diferentes definições, muitas vezes quase sinónimas de skill, atributo, aptidão, qualificação ou capacidade. Boterf (2005) refere, por exemplo, que o conceito de competência foi associado, de forma redutora, à utilização de saberes num dado contexto, a um conjunto de capacidades ou a características dos sujeitos.

Ainda na mesma linha, autores como Eraut (1997) distinguem o termo competência de competências na capacidade das pessoas em elaborar e desenvolver atitudes face a uma dada situação versus os conhecimentos que cada um tem sobre determinado objeto: "the term competence (...) refers to a person overall capacity, and the term competency is (...) simply to describe any piece of knowledge or skill that might be constructed as relevant" (p. 179). Já Perrenoud (2001) considera necessário distinguir competência de capacidade, de forma a clarificar ambos os conceitos. Para este autor, capacidades seriam as operações e/ou atividades que não têm em consideração a especificidade da situação, sendo independentes do contexto. Relativamente às competências, estas implicam a mobilização e integração de recursos cognitivos diversos, procurando responder a situações concretas. Neste quadro, as capacidades serão elementos constitutivos das competências. Esta definição vai ao encontro da de autores como Rué e Martínez (2005) que entendem competência como a faculdade de mobilizar um conjunto de recursos cognitivos e práticos - como conhecimentos, motivações, valores, atitudes ou emoções - para solucionar pertinente e eficazmente uma situação ou conjunto de situações, não podendo ser independente do contexto dos intervenientes. A competência é, assim, algo que é localizado no indivíduo, sendo independente dos recursos de mediação utilizados e sendo transferível a outras situações ou tarefas de uma forma mecânica.

Adotou-se, nesta investigação, o conceito de competência como a combinação de "habilidades práticas e cognitivas, conhecimentos - conscientes e implícitos - motivações, valores éticos, visões, emoções e outros aspetos de comportamento social que se combinam para influenciar as decisões individuais e ações na vida profissional e pessoal" (BRASLAVSKY, 2005, p.96). A competência não é entendida como um estado, mas sim como algo que se revela e se desenvolve na ação, criada num processo contínuo passível de alterações 
ao longo do desenvolvimento de cada sujeito, implicando a capacidade de mobilização do saber, dentro de um dado contexto. A competência acontece sempre na relação do sujeito com o coletivo, revelando-se e desenvolvendo-se nesse mesmo coletivo.

Ainda no campo do conceito de competência, importa refletir sobre a transformação genérica a que assistimos no campo social que terá inevitavelmente de ser transposta para o meio escolar - ajustando os instrumentos de aprendizagem e a própria aprendizagem às necessidades da sociedade atual e futura - pelas implicações diretas que esse processo tem nas competências desenvolvidas por alunos e por professores (TRILLING \& FADEL, 2009).

Segundo Silva (2009), o termo competência para o século XXI (ou XXI century skills) quando utilizado em educação é vago, já que reúne em si competências diversificadas de diferentes domínios (como competências práticas, transversais ou técnicas), competências pessoais e competências que não são específicas ao século XXI, sendo a ênfase colocada nos processos cognitivos de análise e de aplicação do conhecimento por parte dos alunos, em detrimento das próprias unidades de conhecimento que detêm. Contudo, apesar de poder ser considerado um conceito difuso, a necessidade de se corresponder às exigências da sociedade atual, em que a resolução de problemas, a tomada de decisões, o trabalho em equipa, o sentido profissional, o sentido ético, a liderança, a gestão e curadoria do conhecimento e o fazer uso das tecnologias digitais são elementos cruciais, levou ao desenvolvimento do conceito de competência para o século XXI (TRILLING \& FADEL, 2009). Segundo estes autores, há quatro forças que em conjunto convergem para novas formas de aprendizagem: Knowledge work (relacionado com os conhecimentos adquiridos e a sua aplicação), Thinking tools (processos cognitivos subsequentes a cada sujeito), Digital lifestyles (relativo aos desenvolvimentos tecnológicos e às suas implicações na sociedade) e Learning research (ligado ao desenvolvimento da aprendizagem e das metodologias de pesquisa de informação), sendo que cada uma destas forças desempenha um papel fulcral para o desenvolvimento de cada pessoa, influenciando consequentemente o processo educativo.

Sendo o termo competência entendido como um constructo que envolve em si mesmo conhecimento, capacidades e processos cognitivos que suportam a mobilização e a integração desses recursos diversos, para responder a situações concretas, a sua aplicação em contexto de sala de aula remete para o desenvolvimento técnico e pedagógico por parte do professor. Desta 


\section{e-Curriculum}

forma, há sempre um envolvimento destas duas dimensões (técnica e pedagógica) em todas as competências docentes (PEDRO, MATOS, PEDRO \& ABRANTES, 2011).

Os mesmos autores realizaram uma meta-análise a 13 frameworks de competências para o século XXI, com base numa revisão de literatura desenvolvida a partir de diferentes bases de dados. Os resultados evidenciaram um conjunto de competências organizadas em diferentes domínios: competências digitais; gestão/organização de informação; capacidade de pesquisa; planificação e resolução de problemas; reflexividade; pensamento crítico, competências de comunicação; colaboração; responsabilidade social; literacia, inovação; criatividade; produtividade e e-business, salientando o aspeto prático, técnico, pedagógico e ético. Embora os frameworks analisados não fossem específicos para a docência, têm servido como base da investigação realizada sobre as competências necessárias aos professores do século XXI, quer numa dimensão mais técnica, quer numa dimensão pedagógica.

Em 2008, a UNESCO publicou o ICT Competency Framework for Teachers, documento revisto em 2011. Este referencial, apesar da sua forte componente relacionada com as tecnologias e a sua utilização, estrutura-se em diferentes níveis de progressão docente, especificando as competências que o professor deve desenvolver durante a progressão na sua profissão, em paralelo ao desenvolvimento que deve potenciar nos seus alunos. O referencial baseia-se em seis domínios de trabalho: (i) Understanding ICT in education; (ii) Curriculum and assessment; (iii) Pedagogy; (iv) ICT; (v) Organization and administration; (vi) Teacher professional learning (UNESCO, 2011). Estes domínios são organizados em três níveis de desenvolvimento profissional docente: Technology Literacy; Knowledge Deepning e Knowledge Creation.

Entende-se, deste modo, que, no domínio das competências para o século XXI para os professores, as competências digitais, de gestão e organização de informação, ligadas à metacognição, à comunicação e à colaboração e aos aspetos éticos e sociais devem ser consideradas como fundamentais, abarcando assim as diferentes dimensões práticas, técnicas, pedagógicas, científicas e éticas.

Utilizando uma dimensão empírica de larga escala, através do questionamento a professores e outros stakeholders, este estudo refletiu sobre as competências fundamentais no desenvolvimento da profissão docente, e identificou as competências técnico-pedagógicas necessárias ao professor do Ensino Básico do século XXI. 


\section{METODOLOGIA}

Este estudo estruturou-se numa abordagem mista de investigação em educação, baseando-se nos pressupostos enunciados por Creswell (2010), Johnson, Onwnergbuzie e Turner (2007) e Tashakkori e Teddlie (1998). Considerando as três estratégias de investigação subjacentes aos métodos mistos indicadas por Creswell (2010) - procedimentos sequenciais, procedimentos concomitantes e procedimentos transformativos - optou-se por uma abordagem concomitante, em que a recolha de dados foi realizada conjuntamente, de forma a que a análise do problema de investigação fosse abrangente, considerando a sua multidimensionalidade. De igual modo, a produção e a interpretação dos resultados foi efetuada mediante a incorporação e a integração dos elementos obtidos a partir dos diferentes tipos de dados recolhidos (de natureza quantitativa e qualitativa).

Por forma a responder à questão central - quais as competências técnico-pedagógicas necessárias ao professor do Ensino Básico do séc. XXI? - recorreu-se ao questionamento de uma amostra aleatória de 2688 professores através de (i) aplicação de uma escala psicométrica de self-report organizada e disponibilizada no formato de um questionário online - Escala de Perceção de Competências Docentes para o Século XXI, PEDRO \& MATOS, 2017) e de (ii) realização de entrevistas, a partir de um guião especificamente preparado para esse fim, a cinco representantes de diferentes estruturas do contexto educativo português, escolhidos por conveniência, Ministério da Educação português; Associação de Pais; Diretores de Instituições de Ensino Superior responsáveis pela formação inicial de professores do Ensino Básico e, por último, Sindicatos de Professores.

Ambos os instrumentos foram organizados em quatro domínios: domínio profissional (DP), domínio pedagógico (DPd), domínio tecnológico (DT) e domínio de relações interpessoais e institucionais (DR). Cada uma dessas quatro dimensões resultou de uma revisão de literatura feita sobre a temática (PEDRO, 2015), tendo para isso sido analisados: (i) referenciais teóricos relativos a competências para o século XXI, (ii) referenciais relativos a competências profissionais de professores, (iii) referenciais de competências TIC e (iv) legislação referente ao desenvolvimento profissional docente. Foram seguidos os pressupostos e a metodologia estabelecida na scoping literature review (ARKSEY \& OMALLEY, 2005; RUMRILL, FITZGERALD \& MERCHANT, 2010). 


\section{e-Curriculum}

\section{RESULTADOS ENCONTRADOS}

Dada a natureza mista da metodologia adotada no estudo, a análise dos dados desta investigação teve um âmbito quantitativo e qualitativo, incidindo igualmente numa relação entre essas duas abordagens (CRESWELL, 2010). A análise seguiu uma estratégia concomitante, em que simultaneamente à codificação nos dados qualitativos se procedeu a uma interpretação dos dados quantitativos, permitindo deste modo uma articulação entre os resultados e a evidência emergente nas duas tipologias (CRESWELL, 2010).

Os resultados foram produzidos a partir duma análise iterativa entre os dados relativos aos professores questionados (provenientes da análise estatística aos resultados obtidos na escala de competências docentes) e os dados relativos às entrevistas realizadas aos stakeholders, optando-se deste modo por uma análise de conteúdo passível de quantificação. Neste processo foram seguidos os princípios definidos por Tashakori e Teddlie (1998) e por Creswell (2010) que salientam a importância da transformação dos dados nas investigações desenvolvidas numa perspetiva metodológica mista concomitante.

$\mathrm{O}$ processo referido permitiu analisar quer as competências que os professores consideravam como significativas ao desenvolvimento da sua profissão, quer as competências que os stakeholders identificavam como essenciais ao desenvolvimento docente, tendo-se posteriormente procedido ao cruzamento de ambos os dados.

No que concerne aos dados resultantes da escala aplicada, optou-se como critério de seleção considerar todas as respostas registadas com valor igual ou superior a 3,5 arredondado à casa decimal (numa escala de 4 pontos, sendo o primeiro entendido como Nada Importante e o quarto como Muito Importante) para cada uma das dimensões identificadas - Dimensão Pedagógica, Dimensão Profissional, Dimensão Tecnológica e Dimensão de Relações Interpessoais e Institucionais.

\subsection{Dimensão Pedagógica}

Os dados obtidos na escala de perceção de competências docentes (dados provenientes da resposta dos professores) mostraram que na dimensão Pedagógica os valores médios foram elevados, tendo-se registado valores médios superiores a 3,5 na maioria das competências deste 
domínio. Os dados indicaram que 12 das competências desta dimensão apresentaram valores médios iguais ou superiores a 3,5, considerando-se estas como significativas.

Os resultados indicaram a importância dada pelos professores a questões relativas à diferenciação de estratégias pedagógicas, com um caráter inovador, considerando quer a diversidade dos alunos e dos seus níveis de aprendizagem, quer questões motivacionais. $\mathrm{Na}$ mesma linha, os docentes realçaram igualmente aspetos ligados à diversidade na utilização de metodologias de trabalho, de forma a contribuir para a criação e produção de materiais e recursos didáticos.

Obedecendo aos princípios de triangulação de dados defendidos pela abordagem metodológica mista adotada neste estudo, os resultados provenientes da análise da escala foram cruzados com os obtidos através da análise às entrevistas realizadas com os stakeholders. Para que fosse possível harmonizar os dados quantitativos (provenientes da escala de perceção aplicada aos professores) com os dados qualitativos (produzidos por análise de conteúdo efetuada às cinco entrevistas realizadas), utilizou-se como critério de análise (de acordo com os princípios explicitados anteriormente) as competências elencadas no instrumento aplicado aos docentes. Entendeu-se como competências essenciais as mencionadas por três ou mais stakeholders, resultando assim em seis competências fundamentais ao desenvolvimento da profissão docente nos próximos cinco anos, sendo que quatro desses itens apresentaram a concordância dos cinco entrevistados.

\subsection{Dimensão Profissional}

No que concerne o domínio Profissional, na escala aplicada aos professores este era composto por 20 itens, nos quais sete obtiveram valores médios iguais ou superiores a 3,5.

As sete competências assinaladas como mais significativas para os professores foram "Refletir sobre as próprias práticas docentes", com um valor médio de 3,76 (e respetivo desviopadrão de 0,458) e "Ter autonomia no domínio profissional" (média de 3,72 e desvio-padrão de 0,468). Realça-se igualmente os itens "Procurar atualização de conhecimento didáticopedagógico" e "Gerir e ser autónomo no desenvolvimento do próprio percurso de desenvolvimento profissional”, ambos com uma média de 3,66 (desvio-padrão de 0,496 e 


\section{e-Curriculum}

0,543, respetivamente), relacionados com aspetos relativos ao desenvolvimento profissional docente e à perceção dos professores sobre este.

A partir das competências que emergiram dos dados obtidos junto dos professores identificaram-se duas tendências na dimensão profissional. Uma, primeira, ligada aos processos autorreflexivos dos docentes - onde se insere a autorregulação, a reflexão sobre as práticas docentes e pedagógicas - e, uma outra, tendência relativa à gestão do próprio desenvolvimento profissional, operacionalizado através da procura de atualização de conhecimento didáticopedagógico e da autonomia tida nesses mesmos processos.

Tendo como base de análise as competências elencadas e apresentadas no instrumento aplicado aos professores, os dados obtidos junto das entrevistas realizadas aos cinco stakeholders permitiram antever que o domínio profissional foi estruturado em torno de seis competências relativas a funções desempenhadas pelos professores na sua prática.

\subsection{Dimensão Tecnológica}

Relativamente à terceira dimensão, a dimensão Tecnológica, consideraram-se as competências ligadas (i) ao conhecimento sobre novos modelos de aprendizagem e consequente integração das tecnologias nesses modelos, e (ii) ao nível de proficiência no uso das tecnologias por parte do professor. À semelhança das dimensões anteriores, os resultados assentaram na análise da escala de perceção aplicada aos professores e na análise de conteúdo realizada às entrevistas efetuadas junto dos stakeholders.

Deste modo, no que concerne à escala de perceção, no domínio Tecnológico o valor médio registado situou-se nos 3,35, com um desvio-padrão de 0,384 , valor situado próximo do ponto três da escala de importância, relativo ao grau Importante, sendo que, das 11 competências que compunham esta dimensão, três foram assinaladas com valores médios iguais ou superiores a 3,5 .

Os dados recolhidos mostram que a competência "Potenciar a escola como espaço de enriquecimento e inovação suportado pela utilização das tecnologias” (Q1) foi assinalada como mais importante no domínio Tecnológico (valor médio de 3,55 e desvio-padrão de 0,525). No entanto a questão "Ser proficiente na utilização de ferramentas digitais e de aplicações online" 
obteve igualmente valores médios elevados (3,54 e desvio-padrão de 0,525). Neste domínio verificaram-se três competências significativas para os professores.

Analisando os dados obtidos junto dos professores participantes percebe-se a resistência que estes ainda demonstram na utilização das tecnologias nas suas práticas letivas. Competências relacionadas com o contributo das tecnologias no processo de ensino e aprendizagem, ou com o reconhecimento das tecnologias como elemento estruturante ao desenvolvimento de pensamento crítico junto dos alunos, não foram consideradas como aspetos fundamentais pelos professores para o desenvolvimento da sua prática docente. Estes resultados encontram-se em consonância com os apresentados por Brás, Miranda e Marôco (2014) ou por Lillejord e colegas (2018), que salientaram que, apesar do imenso desenvolvimento tecnológico das últimas décadas, os professores ainda apresentam resistências à alteração das suas práticas letivas.

Estes dados tornam-se preocupantes na medida em que a investigação mostra que experiências letivas inovadoras e eficazes ocorrem quando os docentes são capazes de desenvolver e estruturar o uso de tecnologias digitais nas suas práticas de ensino (DALY, PACHLER \& PELLETIER, 2009), considerando-se deste modo que o desenvolvimento de competências TIC de âmbito pedagógico e tecnológico é fulcral ao suporte do processo de ensino e de aprendizagem (BALANSKAT, 2010).

De forma a complementar os dados obtidos junto dos professores, e obedecendo aos princípios definidos pela metodologia mista norteadora desta investigação, apresenta-se igualmente os resultados obtidos através da realização de entrevistas aos stakeholders. Neste campo definiram-se seis competências técnico-pedagógicas relacionadas com a utilização de tecnologias e de ferramentas de comunicação em contexto educativo que, após a análise de conteúdo efetuada. Analisando esses dados é possível verificar que a dimensão tecnológica revelou uma maior discrepância nas respostas dadas pelos stakeholders, sendo que apenas numa questão houve ausência de registo, nomeadamente "Ter consciência legal e ética na utilização de tecnologias".

Considerando os resultados obtidos por ambos os grupos de participantes desta investigação foi possível identificar um conjunto de competências tecnológicas que abarcam domínios técnicos, pedagógicos, éticos e sociais. 


\section{e-Curriculum}

\subsection{Dimensão Das Relações Interpessoais E Institucionais}

O último domínio em análise prendeu-se com as Relações Interpessoais e Institucionais, onde se procurou percecionar a importância de competências relacionadas com (i) interações pessoais e profissionais desenvolvidas entre professores e entre estes e os órgãos de gestão escolar e restante comunidade escolar, (ii) aspetos relativos à organização do meio escolar e (iii) gestão das relações entre o docente e os encarregados de educação, funcionários escolares ou entre pares.

Do mesmo modo que nas três dimensões anteriores, a análise do papel desempenhado por estas competências no desenvolvimento da profissão docente para o século XXI assentou em dados provenientes da aplicação da escala de perceção de competências aplicada aos professores e das entrevistas realizadas aos decisores políticos e educativos.

Analisando primeiramente o instrumento aplicado aos professores, obteve-se nesta dimensão um valor médio de 3,38 com um desvio-padrão de 0,360 , valor mais baixo das quatro dimensões consideradas. Composta por 11 itens, cinco dos itens desta dimensão registaram valores iguais ou superiores a 3,5, tendo um dos itens um valor perto dos 4 pontos (referente a Muito Importante).

Relativamente a este domínio foram assinaladas pelos 2688 professores participantes na investigação cinco competências significativas para o desenvolvimento da sua profissão nos próximos cinco anos. Analisando esses dados realça-se (i) o facto de duas das competências identificadas se referirem a aspetos éticos e culturais relativos à articulação da atividade do professor com a comunidade envolvente, e (ii) três das competências estarem relacionadas com o trabalho cooperativo dos docentes e com a interação destes enquanto agentes da comunidade educativa envolvente. Estes dados foram também cruzados com os obtidos junto dos stakeholders. Em consequência, nesta dimensão estruturaram-se dez competências relacionadas com a organização do meio escolar e/ou a gestão das relações entre o docente e os encarregados de educação, funcionários escolares e entre pares. Após a análise de conteúdo efetuada às entrevistas dos cinco participantes apenas uma das competências foi indicada: "Perspetivar o trabalho com pares como fator de enriquecimento da profissão".

Esta última dimensão obteve o menor número de referências por parte dos stakeholders aquando do questionamento relativo às competências que consideravam necessárias que o 
professor do ensino básico desenvolvesse. Associando-se ao desenvolvimento profissional docente, apenas o item "Perspetivar o trabalho com pares como fator de enriquecimento da profissão" foi referido pela totalidade dos decisores educativos.

Sintetizando, os valores encontrados em relação à escala de competências docentes para o século XXI, apontadas pelos 2688 professores, salientaram valores médios favoráveis no que concerne às competências indicadas, estando os valores mais reduzidos associados a competências relativas a aspetos de ordem externa ao professor, tais como a articulação deste com a gestão da escola ou com outros intervenientes no processo educativo. Por outro lado, as competências relativas à prática pedagógica do docente apresentam médias elevadas, próximas do valor máximo (Muito Importante), referente a quatro pontos na escala. Estes resultados verificaram-se igualmente na análise dos dados descritivos das dimensões, onde é possível percecionar a dimensão pedagógica da docência como fator de relevo para a carreira de professor.

Os resultados vão assim ao encontro daqueles que foram identificados em diferentes estudos que concluem que, apesar da necessidade de se considerar a multidimensionalidade da docência como fator fundamental desta profissão permitindo uma conceção desta como profissão complexa, os professores continuam a privilegiar as competências pedagógicas como elemento estruturante da função do professor. O cruzamento dos resultados obtidos no movimento de triangulação entre os dados provenientes dos docentes e dos decisores políticos e educativos, resultou assim num conjunto de 37 competências, organizadas pelas quatro dimensões (DPd - 14; DP - 12; DT - 6; DR - 5).

Quadro 1: Competências docentes para o século XXI

\begin{tabular}{|l|l|}
\hline & Promover o desenvolvimento de autonomia dos alunos \\
\hline $\begin{array}{l}\text { Criar situações de aprendizagem para os alunos desenvolverem pensamento } \\
\text { crítico e resolução de problemas }\end{array}$ \\
\hline $\begin{array}{l}\text { Procurar atualização de conhecimento científico } \\
\text { Pedagógica }\end{array}$ & $\begin{array}{l}\text { Identificar as diferenças pessoais dos alunos } \\
\text { letivas }\end{array}$ \\
\hline $\begin{array}{l}\text { Flexibilizar as práticas letivas perante a diversidade de situações e saberes } \\
\text { prévios dos alunos }\end{array}$ \\
\hline Aplicar metodologias de acompanhamento didático dos alunos \\
\hline Elaborar atividades de aprendizagem que estimulem os alunos \\
\hline Utilizar diferentes estratégias de ensino \\
\hline
\end{tabular}




\section{$e$-Curriculum}

Programa de Pós-Graduação em Educação: Currículo

Utilizar de forma integrada saberes da sua especialidade e saberes transversais e multidisciplinares

Criar, em contexto de sala de aula, situações de aprendizagem focadas na resolução de problemas reais

Desenvolver estratégias pedagógicas diferenciadas

Desenvolver conhecimento didático adequado à área disciplinar

Gerir o currículo mediante as necessidades de cada turma

Refletir sobre as próprias práticas docentes

Lidar com situações relacionadas com a gestão de riscos na relação educativa Procurar situações e contextos informais de aprendizagem e de desenvolvimento profissional

Ter autonomia no domínio profissional

Refletir sobre o próprio pensamento (processos metacognitivos)

Autorregular-se no processo ensino e de aprendizagem

Dimensão
Profissional

Procurar atualização de conhecimento didático-pedagógico

Participar em ações de formação continua

Elaborar estratégias de partilha de recursos

Gerir e ser autónomo no desenvolvimento do próprio percurso de desenvolvimento profissional

Refletir sobre as suas práticas pedagógicas

Reconhecer a dimensão cívica e formativa das suas funções enquanto professor

Potenciar a escola como espaço de enriquecimento e inovação suportado pela utilização das tecnologias

Possuir conhecimentos técnicos específicos para trabalhar com alunos com

Dimensão

Tecnológica

necessidades educativas especiais

Ser proficiente na utilização de ferramentas digitais e de aplicações online

Reconhecer a tecnologia como presente nas práticas dos alunos

Aplicar ferramentas digitais e de aplicações online no processo ensino e de aprendizagem

Utilizar as tecnologias digitais como ferramenta para desenvolver pensamento crítico dos alunos

Atuar de forma socialmente responsável

Dimensão

Perspetivar o trabalho com pares como fator de enriquecimento da profissão

Relações

Interpessoais e

Colaborar com todos os intervenientes no processo educativo, favorecendo o Institucionais desenvolvimento de relações entre os vários agentes educativos

Identificar e respeitar as diferenças culturais dos alunos e restante comunidade Colaborar e cooperar com a comunidade escolar

Fonte: Pedro (2015)

Relativamente ao domínio Pedagógico, indicam-se 14 competências para o século XXI, estruturadas em torno do desenvolvimento de práticas pedagógicas inovadoras e metodologias de trabalho potenciadoras de flexibilização de conteúdos, currículo e estratégias de ensino e de aprendizagem. Assinala-se igualmente a preocupação demonstrada com fatores ligados à aproximação do mundo real, tornando assim as experiências letivas e as aprendizagens 
realizadas contextualizadas face à realidade, diminuindo por consequência o desfasamento entre a sociedade e a escola referido por diferentes autores (ACETO ET AL., 2014; BRÁS ET AL., 2014; COUTINHO, 2009; 2011; DAVIS \& ROBLYER, 2005; KIBRICK ET AL., 2010; MATOS \& PEDRO, 2011; PEDRO ET. AL, 2012; SCHLEICHER, 2011; UNESCO, 2008; 2011).

Se analisarmos os dados obtidos neste domínio em comparação com os referenciais de competências para o século XXI estruturados para os alunos ou para os cidadãos em geral, podemos antever que existe uniformidade nos resultados obtidos junto dos docentes e dos decisores políticos participantes. Assim, à semelhança do encontrado nos trabalhos desenvolvidos por organizações como a enGauge 21st Century skills (2009), a ISTE (2008), a Partnership for 21-st century-skills (2009) ou a OCDE, os resultados deste estudo indicam que a capacidade de pesquisa, de gestão e organização de informação, do desenvolvimento de pensamento crítico ou da planificação e resolução de problemas, são apresentadas como competências para o século XXI a desenvolver nos professores do ensino básico.

No mesmo sentido, os resultados obtidos na dimensão profissional evidenciam uma preocupação com aspetos ligados aos processos metacognitivos e reflexivos, fundamentais para a autonomia pedagógica e a atualização do próprio conhecimento. Neste domínio, os resultados mostraram igualmente a importância de fatores relacionados com a gestão de riscos e com o reconhecimento da dimensão cívica do professor.

Os resultados encontrados neste estudo mostram que os 2688 docentes e os decisores políticos e educativos questionados consideraram como relevante para o desenvolvimento profissional docente entender-se a escola como um espaço de enriquecimento e inovação suportado pela utilização das tecnologias digitais, reconhecendo consequentemente a tecnologia como algo necessariamente presente nas práticas dos alunos. A utilização das tecnologias digitais como ferramenta para desenvolver pensamento crítico dos estudantes foi igualmente referida como elemento estrutural ao desenvolvimento docente.

Simultaneamente, estes participantes consideraram como competências para o século XXI a desenvolver conhecimentos de ordem técnica para aplicar na estruturação do processo de ensino e de aprendizagem. Verifica-se novamente uma aproximação destes resultados com as competências para o século XXI apresentadas em referenciais para alunos (encontradas no referencial de instituições como Partnership for 21 st century skills ou Institute for Prospective 


\section{e-Curriculum}

Technological Studies), onde se considera primordial o desenvolvimento de competências digitais, a construção de pensamento crítico e a sua potenciação nos outros e a necessidade de inovar. No entanto, realça-se que os aspetos ligados à responsabilidade social e ao caráter ético na utilização das tecnologias não foram referidos nos dados desta investigação, colocando assim como fator secundário o desenvolvimento de competências ligadas quer à identidade e cidadania digitais, quer à consciência ética global e local.

Relativamente ao domínio de relações interpessoais e institucionais, os resultados salientaram que os fatores relacionados com o trabalho colaborativo foram indicados como essenciais a um professor competente para o século XXI, indo ao encontro do estabelecido por diversos autores (PERRENOUD, 2000; ESTEVE, 2009; NÓVOA, 2009) que referem que o trabalho entre pares pode funcionar como elemento estruturador a um desenvolvimento profissional docente eficaz.

\section{CONCLUSÃO}

O objetivo estrutural desta investigação referia-se à identificação das competências necessárias aos professores do ensino básico, considerando a perceção destes e dos decisores políticos sobre quais os aspetos a considerar para se ser um professor competente no século XXI. Neste ponto, obtivemos junto de 2688 professores e de cinco stakeholders resultados que evidenciaram 37 competências necessárias ao desenvolvimento profissional do professor. Os dados consideraram a multiplicidade de saberes e conhecimentos fundamentais ao professor, abarcando aspetos reflexivos, metacognitivos, práticos, técnicos, sociais e intelectuais.

Os resultados apresentados evidenciam um maior peso da dimensão pedagógica, tendo esta o maior número de competências indicadas. Consolida-se a ideia de que é essencial para o professor (i) dominar e desenvolver os conteúdos das disciplinas que leciona, (ii) construir e produzir materiais pedagógicos que contribuam para a aprendizagem dos seus alunos, (iii) estruturar estratégias de ensino inovadoras que contribuam para uma maior motivação (sugerese por exemplo metodologias de trabalho como o mobile learning ou game based learning), e (iv) refletir sobre os processos metacognitivos dos seus alunos.

Os participantes do estudo consideraram ainda que o domínio profissional permanece como elemento estrutural ao desenvolvimento docente, combinando diferentes saberes e 
contributos que, entendidos como um todo e resultantes da interação do docente com o meio, possibilitarão uma construção efetiva da noção de profissionalidade (NÓVOA, 2009).

Os resultados indicaram também que a utilização das tecnologias digitais na estruturação da sua atividade docente e a consciencialização do seu uso para a construção de conhecimento nos seus alunos, é um elemento estrutural. Assinala-se assim o reconhecimento, por parte dos professores inquiridos, do papel que as tecnologias digitais podem desempenhar como contributo para um processo de ensino e de aprendizagem de sucesso (VONGKULLUKSN, XIE \& BOWMAN, 2018).

Por último, os resultados na dimensão relativa às relações interpessoais e interinstitucionais apresentaram valores que, apesar de serem entendidos com algum grau de importância, salientam que as competências ligadas à colaboração e ao trabalho entre pares não são ainda consideradas como fundamentais pelos professores. Estes resultados suscitam uma maior preocupação se considerarmos que, numa sociedade fortemente tecnológica onde se defende a colaboração como fator de sucesso e de progressão, os professores continuam a ser uma classe profissioal com pouca visão acerca das virtualidade e benefícios do trabalho colaborativo. Neste sentido, a existência de uma dificuldade de colaboração tenderá a fazer surgir constrangimentos na criação de comunidades informais, onde se potencie $o$ desenvolvimento docente.

Considerando os resultados enunciados anteriormente, torna-se consensual considerar a necessidade de refletir sobre as novas competências a desenvolver pelos professores, procurando assim responder às necessidades apresentadas pela sociedade e pelos alunos e, consequentemente, contribuir para um melhor sistema educativo. $\mathrm{O}$ desenvolvimento deste paradigma educativo, centrado no professor e no aluno enquanto agentes do seu próprio desenvolvimento (LEITÃO \& ALARCÃO, 2006), representará um passo para uma estruturação do processo de ensino e de aprendizagem mais motivadora para os seus intervenientes.

Do mesmo modo, ao se entender as competências docentes para o século XXI como fator estrutural para a alteração de práticas letivas, contribuir-se-á para uma adequação da escola à evolução tecnológica (COUTINHO, 2011; MATOS \& PEDRO, 2011; PATROCÍNIO, PEDRO \& MATOS, 2014), elemento essencial a considerar na formação docente, inicial e contínua. Sugere-se, consequentemente, que os resultados aqui apresentados sejam entendidos 


\section{e-Curriculum}

como um contributo para uma reflexão necessária sobre as estratégias a incluir na formação docente, que, por um lado, visem o desenvolvimento de competências (já identificadas pelos professores e pelos decisores políticos) e, por outro, potenciem um desenvolvimento docente efetivo, assente nas práticas do professor e considerando a relação deste com o meio onde se insere. Assim, as futuras formações de professores (iniciais ou contínuas) devem assentar as suas atividades de formação em metodologias e estratégias de trabalho, que contribuam para o desenvolvimento de competências para o século XXI apresentadas neste referencial.

\section{REFERÊNCIAS}

ACETO, Stefania, BOROTIS, Spiros, DEVINE, Jim; FISCHER, Thomas. Mapping and Analysing Prospective Technologies for Learning. Results from a consultation with European stakeholders and roadmaps for policy action. JRC Scientific and Policy Reports. Seville, 2014.

ARKSEY, Hillary; O'MALLEY, Lisa. Scoping studies: towards a methodological framework. International Journal of Social Research Methodology, 8:1, 2005, p.19-32.

BALANSKAT, Anja. The study of the impact of technology in primary schools (STEPS): Synthesis report, 2010.

BATANE, Tshepo; NGWAKO, Abraham. Technology use by pre-service teachers during teaching practice: Are new teachers embracing technology right away in their first teaching experience? Australasian Journal of Educational Technology, 33(1), 2017.

BOTERF, Guy. Construir as Competências Individuais e Colectivas. Colecção Ficheiros Pedagógicos para Professores. Porto: Edições Asa, 2005.

BRÁS, Pedro; MIRANDA, Guilhermina; MARÔCO, João. Teachers and technology: A complicated relationship. GSTF International Journal on Education, 2 (1), 2014, p.56-65.

BRASLAVSKY, Cecilia; BORGES, Carla; SIMAO, Marcelo Souto; TRUONG, Nhung. Historical Competence as a Key to Promote Democracy. In: IBE/UNESCO. School Knowledge in Comparative and Historical Perspective: Changing Curricula in Primary and Secondary Education. Geneva: IBE/UNESCO, 2006.

CONCEIÇÃO, Cristina; SOUSA, Óscar. Ser professor hoje. O que pensam os professores das suas competências. Revista Lusófona de Educação, 2012, p.20.

COUTINHO, Clara. Challenges for teacher education in the learning society: Case studies of promising practice. In: H. H. Yang \& S. H. Yuen (eds.). Handbook of research and practices in E-Learning: Issues and Trends. Hershey, New York: Information Science Reference - IGI Global, 2009. p. 385-401. 
COUTINHO, Clara. TPACK: Em busca de um referencial teórico para a formação de professores em tecnologia educativa. Revista Paidéi@. UNIMES VIRTUAL, Vol. 2, N.4, 2011.

CRESWELL, John William. Projeto de pesquisa. Métodos qualitativo, quantitativo e misto. 3. Ed. Porto Alegre: Artmed, 2010.

DALY, Caroline; Pachler, Norbert; Pelletier, Caroline. Continuing professional development in ICT for teachers: A literature review. London: BECTA, 2009.

DAVIS, Niki; Roblyer, M. Preparing teachers for the "schools that technology built". Journal of Research on Technology in Education, 37, 4, 2005, p. 399-409.

ERAUT, Michael. The balance between Communities and Personal Agency: Transferring and integrating knowledge and know-how between different communities and contexts. Learning to be Professional through a Higher Education E-BOOK, 2012.

ESTEVE, José Manuel. La formación de profesores: bases teóricas para el desarrollo de programas de formación inicial. Revista de Educacion, 350, 2009, p. 203-218

ESTEVES, Manuela. Construção e desenvolvimento das competências profissionais dos professores. Sísifo - Revista de Ciências da Educação, 08, 2009, p. 37-48.

JESUS, Saul Neves. Motivação e formação de professores. Coimbra: Quarteto Editora, 2000.

JOHNSON, Burke; ONWUEGBUZIE, Anthony; TURNER, Lisa. Toward a Definition of Mixed Methods Research. Journal of Mixed Methods Research, 1, 2007, p. 112-133.

LEITÃO, Álvaro; ALARCÃO, Isabel. Para uma nova cultura profissional: uma abordagem da complexidade da profissão na formação inicial de professores do $1^{\circ} \mathrm{CEB}$. Revista

Portuguesa da Educação, 19 (2), 2006, p. 51-84.

LILLEJORD, Sølvi; BØRTE, Kristin; NESJE, Katrine; RUUD, Erik. Learning and teaching with technology in higher education - a systematic review. Oslo: Knowledge Centre for Education, 2018.

MATOS, João Filipe; PEDRO, Ana. Porquê integrar o lápis no currículo do ensino básico? Reflexão sobre a problemática das tecnologias na educação. Atas VI Conferência Internacional TIC na Educação - Challenges. Braga: Universidade do Minho, 2011. NETS. The ISTE NETS and Performance Indicators for Teachers, 2008.

NÓVOA, António. Profissão Professor. Porto: Porto Editora, 2003.

OECD. Building a High-Quality Teaching Profession. Lessons from around the world, Paris: OECD Publishing, 2011. 


\section{e-Curriculum}

OECD. Innovating Education and Educating for Innovation: The Power of Digital

Technologies and Skills. Paris: OECD Publishing, 2016.

Partnership for 21-st century skills. Framework for 21st Century Learning, 2009. Retirado de http://www.p21.org/index.php?option=com_content\&task=view\&id=254\&Itemid=120. Acesso em: 15 nov. 2018.

PATROCÍNIO, Pedro; PEDRO, Ana; MATOS, João Filipe. 21st Century Skills and Mobile Learning: The relationship between two constructs. Proceedings of SGEM2014 Conference on Psychology and Psychiatry, Sociology, Healthcare and Education, 2014. DOI: 10.5593/sgemsocial2014/B13/S3.031

PEDRO, Ana. Tecnologias e competências dos professores do ensino básico para o séc. XXI. Tese (Doutoramento em Educação) - Instituto de Educação, Universidade de Lisboa, 2015.

PEDRO, Ana; MATOS, João Filipe. Validação da escala de perceção de competências docentes para o século XXI. Revista Intersaberes, v.12, n²6, 2017, p. 212-227. DOI: http://dx.doi.org/10.22169/revint.v12i26.1308

PEDRO, Neuza; MATOS, João Filipe; PEDRO, Ana; ABRANTES, Paula. Teacher Skills and competence development for classrooms of the future. European Schoolnet: ITEC Report, 2011. Disponível em:

$<$ http://itec.eun.org/c/document_library/get_file?p_1_id=10307\&folderId=37321\&name=DLF E-2213.pdf $>$ Acesso em: 15 novembro de 2018.

PEDRO, Neuza; WUNSCH, Luana; PEDRO, Ana; ABRANTES, Paula. Tecnologias, inovação e desenvolvimento profissional docente no século XXI (ou, pergunte-se aos alunos o que os professores precisam de aprender). Atas $1^{\circ}$ Encontro Internacional TIC e Educação. Lisboa: Instituto de Educação da Universidade de Lisboa, 2010.

PERRENOUD, Philippe. Dez novas competências para uma nova profissão. Pátio. Revista Pedagógica, 17, 2001, p. 8-12.

RUMRILL, Phillip; FITZGERALD, Shawn; MERCHANT, William. Using scoping literature reviews as a means of understanding and interpreting existing literature. Work, 35(3), 2010, p. 399-404.

RUÉ, Domingo; MARTÍNEZ, Maite. Las titulaciones UAB en el Espacio Europeo de Educación Superior. Sistema Europeo de Transferencia de Créditos. Colección Eines, 1, 2005. Barcelona: Universidad Autónoma de Barcelona.

SILVA, Elena. Measuring skills for 21st-century learning. Phi Delta Kappan, 90(9), 2009, p. 630-635.

Tashakkori, Abbas; Teddlie, Charles. Mixed Methodology: Combining Qualitative and Quantitative Approaches (Vol. 46). Thousand Oaks, CA: Sage Publications, 1998. 
TRILLING, Bernie; FADEL, Charles. 21st century skills: learning for life in our times. San Francisco: Jossey-Bass, 2009.

VONGKULLUKSN, Vanessa; XIE, Kui; BOWMAN, Margaret. The role of value on teachers' internalization of external barriers and externalization of personal beliefs for classroom technology integration. Computers \& Education, 118, 2018, pp. 70-81. https://doi.org/10.1016/j.compedu.2017.11.009.

Financiamento:

Este texto foi desenvolvido no âmbito do Projeto Technology Enhanced Learning @ Future Teacher Education Lab financiado pela Fundação para a Ciência e Tecnologia com a referência PTDC/MHC-CED/0588/2014 